\title{
Characterization of porous nickel-free austenitic stainless steel prepared by mechanical alloying
}

\author{
C. Garcia-Cabezon a, Y. Blanco a, M.L. Rodriguez-Mendez ${ }^{\text {b }}$, F. Martin-Pedrosa a, * \\ ${ }^{a}$ Materials Engineering, E.I.I., Universidad de Valladolid, C/ Paseo del Cauce 59, 47011 Valladolid, Spain \\ ${ }^{\mathrm{b}}$ Department of Inorganic Chemistry, E.I.I., Universidad de Valladolid, C/ Paseo del Cauce 59, 47011 Valladolid, Spain
}

\section{A R T I C L E I N F O}

\section{Article history:}

Received 12 January 2017

Received in revised form

1 May 2017

Accepted 5 May 2017

Available online 6 May 2017

\section{Keywords:}

Metals and alloys

Powder metallurgy

Mechanical alloying

Corrosion

Microstructure

Metallography

\begin{abstract}
A B S T R A C T
Nickel-free austenitic powder metallurgy stainless steels were prepared and characterized. The main issue was to obtain potential biocompatible materials. Mechanical alloying in a nitrogen atmosphere was used to obtain these powders. The main factor to be controlled was the milling time. Powder metallurgy was the technique to obtain massive samples from alloyed powders. Two sintering processes were applied by controlling the sinter-cooling rate (furnace and water-cooling). The sintering atmosphere applied was nitrogen because of its gammagenic effect. Samples made of powders milled for $48 \mathrm{~h}$, sintered in nitrogen and water-cooled showed a clean austenitic microstructure, which is a suitable microstructure for biological applications. A complete microstructural characterization, including optical metallography, image analysis, Scanning Electron Microscopy with X-ray microanalysis, X-Ray diffraction and Vickers hardness and microhardness, was carried out. The electrochemical behaviour in a simulated body fluid, phosphate buffered saline, was also studied. The biocorrosion behaviour was evaluated in terms of anodic polarization measurements.
\end{abstract}

() 2017 Elsevier B.V. All rights reserved.

\section{Introduction}

Nickel-free austenitic stainless steels (SS) are becoming materials of great interest, especially for biomedical applications where allergy problems can be present. These steels are replacing the traditional stainless steels such as AISI 316L for different reasons as they are biocompatible, show good mechanical properties and good corrosion behaviour [1,2].

Nickel must be replaced by some other alloying elements in order to obtain these new alloys and nitrogen is a good candidate. It is an austenite stabilizer, is biocompatible and, in solid solution, improves both mechanical properties and corrosion resistance [3-6]. Unfortunately, alloying steel with nitrogen is not an easy task. Some complex methods, such as nitrogenization of surfaces in nitrogen gas at $1200{ }^{\circ} \mathrm{C}$, have been developed [7]. High-pressure melting techniques [8] are used to obtain conventional high nitrogen SS, which requires expensive equipment. Alternatives to these two are some processes in solid state as nitrogen solubility is higher than for SS in melted state [9]. One of these methods is by

\footnotetext{
* Corresponding author.

E-mail address: fmp@eii.uva.es (F. Martin-Pedrosa).
}

mechanical alloying (MA) [10], followed by a powder metallurgy (PM) process such as simple compaction and sintering. Milling adequate powders in a nitrogen atmosphere [11,12] or, as an alternative, milling powders with nitrides under an inert gas atmosphere [13], are two possible methods.

The phase analysis and thermal stability studies showed that the structure of the powders obtained by MA under nitrogen atmosphere is transformed from ferrite-phase into a mixture of austenite and amorphous phase as the milling time increases $[14,15]$. However, when milling in argon atmosphere, the structure contains a predominantly ferrite phase and a trivial amount of amorphous phase. Grain refinement is observed when milling in nitrogen atmosphere [12,16,17]. Tehrani et al. [11] investigated the effect of the chemical composition, mainly manganese and nitrogen, on the ferrite/austenite ratio of the SS powders obtained by MA as a function of the milling time. The nitrogen content is enhanced by decreasing the amount of Mn. The ferriteaustenite transformation rate decreased when the Mn content was reduced.

Most of the published works focus on the characterization of FeCr-Mn-N powders obtained by MA [11-16], but none of them deal with their potential applications. Atmosphere and milling time are the typical factors studied. The main conclusion is that a nitrogen 
atmosphere and long milling times favour amorphization [18]. A magnetic characterization shows that, after a full amorphization, the powders are paramagnetic. Only after some heat treatments can this state be changed $[12,17,19]$. The micro-hardness of these powders, after a uniaxial cold-pressed process, is also evaluated $[17,20]$. Some of these powders are sintered in a vacuum in quartz tubes and the effect of the sintering conditions on the densification and mechanical properties are studied. A full austenitic SS is obtained after $20 \mathrm{~h}$ of sintering [21]. The density decreases and the mechanical properties increase by increasing the milling times [21]. In addition, the wear behaviour of these porous materials is investigated, and the material exhibited wear losses similar to 316L SS [22].

The PM processes provide a feasible and economical manufacturing of austenitic SS components with complex shapes for biomedical applications. In recent years, metallic porous materials have attracted much interest as candidates for biomedical applications as the gradual porosity is an essential parameter in implantology [23]. The inherent porosity of powder metallurgy materials is not necessarily a drawback for the field of implantology, since pores in the prosthesis improve the fixation and enhance the bone ingrowth and osseointegration [24,25]. However, it is true that the mechanical properties and corrosion resistance of PM stainless steels are lower than those of either cast or wrought stainless steels [26].

It is not currently possible to get commercial $\mathrm{Ni}$-free austenitic SS powders. The authors have been working with SS powders of high nitrogen and low nickel provided by Höganäs, but some nickel is still therefore present and it may still potentially cause allergic problems [26]. Recently, nanocrystalline medical-grade nickel-free SS has been prepared by PM using powders supplied by Merck ([27]). These were liquid-phase sintered with Mn-Si additive in a vacuum. The effect of the additive content and sintering temperature on the structure and mechanical properties are analysed [28]. The theoretical PREN (Pitting Resistance Equivalent Number) is used to calculate the pitting corrosion resistance. The powders obtained by MA are a different alternative which is explored in this work. In this sense, Salahinejad et al. demonstrated the interest of mechanical alloying and subsequent annealing in the development of nanostructured medical-grade SS [29].

The biocorrosion of metal implants is critical, as it can adversely affect biocompatibility and mechanical integrity. There are many studies on the characterization and enhancement of the corrosion resistance, although all of them concern conventional austenitic SS for medical applications. Kocijan et al. studied the corrosion behaviour of 316L under both open circuit potentials and potentiostatic conditions [30] and using potentiodynamic measurement in artificial saliva [31]. Karimi et al., used OCP (Open Circuit Potential), potentiostatic and potentiodynamic experiments in phosphate buffered saline (PBS) [32]. Shahryari et al. [33] studied the general and pitting corrosion resistance of a biomedical grade 316 SS by electrochemical cyclic voltammetry in PBS. This media is used in this work for porous materials as an inorganic solution to simulate the corrosiveness of body fluids.

This work has several objectives. First, to obtain and characterize nickel-free austenitic SS powders by means of mechanical alloying. Second, to sinter some PM samples in nitrogen or in a vacuum, and cooling from sintering in a fast or slow way. Milling time and sintering parameters are analysed. Such techniques as optical microscopy, SEM/EDS (Scanning Electron Microscopy with X-ray microanalysis), XRD (X-Ray Diffraction) and image analysis are used to characterize the samples. Hardness and magnetic properties are also evaluated. The Ni-free austenitic SS is characterized for medical applications by Anodic Polarization (AP) in a typical biological environment such as PBS.

\section{Materials and methods}

\subsection{Materials}

Elemental powders of Fe (10 $\mu \mathrm{m}, 99.5 \%$ purity $), \mathrm{Cr}(<300 \mu \mathrm{m}$, 99\% purity), Mn ( $<100 \mu \mathrm{m}, 99 \%$ purity) supplied by Merck and C (30 $\mu \mathrm{m}, 99.9 \%$ purity) supplied by Mersen USA were used as the raw materials for mechanical alloying. A mixture of $73.97 \mathrm{wt} . \% \mathrm{Fe}$, 18 wt.\% Cr, 8 wt.\% $\mathrm{Mn}$ and 0.03 wt.\% C was chosen because it is exactly the mixture chosen by Salahinehad et al. [20] to obtain austenitic SS. MA was performed in a standard ball mill of OrtoAlresa, Model OABM255, with SS balls ( $8 \mathrm{~mm}$ in diameter) and a ball-to-powder weight ratio of $20: 1$ under $\mathrm{N}_{2}-\mathrm{H}_{2}(95 \%-5 \%)$ atmosphere at initially 2 bar. A rotation speed of $300 \mathrm{rpm}$ was selected and six milling times were chosen: 24, 36, 48, 72 and 96 h. Oxygen content for any sample was around $0.20-0.25$ wt.\%. The nitrogen content for every powder was lower than $0.05 \mathrm{wt} . \%$, which means the nitrogen, at this step, was acting as a protective atmosphere. No nitrogen alloying was then obtained.

Disc specimens (12 $\mathrm{mm}$ in diameter and $6 \mathrm{~mm}$ in height) were uniaxially compacted at $750 \mathrm{MPa}$ for $300 \mathrm{~s}$ using a floating die and zinc stearate as die lubricant. Some samples were sintered at $1175{ }^{\circ} \mathrm{C}$ in $\mathrm{N}_{2}-\mathrm{H}_{2}(95 \%-5 \%)$ for $60 \mathrm{~min}$ and some others were sintered at the same temperature and time but in a vacuum. After this 60 min of sintering time, two alternative sinter-cooling processes were introduced for samples sintered in nitrogen atmosphere. Some samples were cooled in the furnace at a slow rate of $5^{\circ} \mathrm{C} / \mathrm{min}$ (referred to from now on as "furnace-cooled" samples). Others were subjected to fast cooling by direct immersion in water from the sintering oven (designated from now on as "water-cooled" samples). For samples sintered in a vacuum, it was not possible to apply the fast cooling process because a very fast oxidation process took place at high temperatures. Therefore, only slow cooling at a rate of $5{ }^{\circ} \mathrm{C} / \mathrm{min}$ was used. The samples were designated as $\mathrm{N}-\mathrm{FC}$ (sintered in nitrogen and furnace-cooled), N-WC (sintered in nitrogen and water-cooled) and V-FC (sintered in a vacuum and furnace-cooled). When required, some N-FC samples were submitted to annealing $\left(1050{ }^{\circ} \mathrm{C}\right.$ for $60 \mathrm{~min}$ in argon atmosphere) and were then designated as N-FC-A. Prior to these symbols, two digits indicate the hours of milling, for example, 48-N-WC means powders with $48 \mathrm{~h}$ of milling, sintered in nitrogen and water-cooled, Table 1.

\subsection{Microstructural characterization}

After sintering and cooling, an image analysis of polished samples was done. The measured parameters were degree of porosity, number of pores, sphericity and pore area. A total of 8 fields at $100 \times$ magnification per sample was chosen.

Density was also determined by the Archimedes method. Samples were polished and etched before observation by optical metallography and SEM/EDS. Vilella and Fry chemical reagents were used, depending on the feature of interest. ASTM A262, Practice A [34], was used to determine the sensitized areas (chromium depleted zones) of the samples. XRD assisted in the identification of the phases. Additionally, some bulk extracted powders were analysed by XRD. Bulk extraction was performed by electrolytic dissolution of the matrix with $10 \% \mathrm{HCl}$ in methanol solution at 5-6 V. Residues were filtered and XRD was performed to identify precipitated secondary phases.

\subsection{Vickers hardness}

The apparent Vickers hardness (i.e. the value obtained when indentation is the result of the plastic deformation of the structure 
Table 1

Notation of the samples as a function of some of the processing parameters.

\begin{tabular}{|c|c|c|c|c|c|c|c|}
\hline Milling time (hours) & Symbol & Sintering atmosphere & Symbol & Cooling from sintering & Symbol & Post-treatment & Symbol \\
\hline \multirow[t]{2}{*}{$24,36,48,72,96$} & $\mathrm{XX}$ & Nitrogen & $\mathrm{N}$ & Water & WC & Annealing & A \\
\hline & & Vacuum & V & Furnace & FC & & \\
\hline
\end{tabular}

and pores) was evaluated by HV 30. Microhardness was also measured by the Vickers test with $100 \mathrm{~g}$ for $30 \mathrm{~s}$. At least seven hardness tests were carried out with acceptable impressions; the two lowest values were discarded and the hardness was considered as the arithmetical mean of the remaining values [35]. The microhardness indentations were taken within circle regions free of visible porosity.

\subsection{Corrosion resistance}

The potentiodynamic anodic polarization curves were done following ASTM standard G-5 [36]. Surface preparation of the samples was performed with $1 \mu \mathrm{m}$ diamond paste polishing. Nitrogen streaming and agitation were used throughout the whole test. The tests were carried out in PBS solution $(0.8 \mathrm{~g} / \mathrm{l} \mathrm{NaCl}, 0.2 \mathrm{~g} / \mathrm{l}$ $\mathrm{KCl}, 0.594 \mathrm{~g} / \mathrm{l} \mathrm{Na} 2 \mathrm{HPO}_{4}, 0.2 \mathrm{~g} / 1 \mathrm{KH}_{2} \mathrm{PO}_{4}$ ) and a temperature of $37{ }^{\circ} \mathrm{C} \pm 1$ and $\mathrm{pH}$ 7.44. A Saturated Calomel Electrode (SCE) was used as reference electrode. The experimental test procedure was as follows: First, a 5 min delay at open circuit (OC) potential was followed by a 2 min anodic attack at $-220 \mathrm{mV}_{\mathrm{SCE}}$; then a delay of $2 \mathrm{~min}$ at $\mathrm{V}_{\mathrm{OC}}$, a $1 \mathrm{~min}$ cathodic cleaning at $-600 \mathrm{mV}_{\mathrm{SCE}}$, a $5 \mathrm{~min}$ delay at OC potential and, finally, an anodic potentiodynamic scan, which started at $50 \mathrm{mV}_{\mathrm{SCE}}$ below $\mathrm{V}_{\mathrm{OC}}$, reaching $1000 \mathrm{mV}_{\mathrm{SCE}}$. The potential scan rate was set at $50 \mathrm{mV} / \mathrm{min}$.

\section{Results and discussions}

\subsection{Characterization of the powders obtained by mechanical alloying}

The XRD patterns of the initial powders are shown in Fig. 1a. It can be seen that Fe and $\mathrm{Cr}$ have a body centred cubic structure $(\alpha$ phase or ferrite for steels), while Mn presents a face centred cubic structure ( $\gamma$ phase or austenite for steels). This last metal has a strong tendency to oxidation, as is also shown in its XRD pattern. The XRD patterns of the MA powders reveal that peaks depend on the milling time (Fig. 1b). The dominant crystalline phase at short milling times was ferrite and the quantity of austenite phase increased by increasing the milling time, becoming relevant at $72 \mathrm{~h}$ of milling. This indicated that the milling of the elemental powders under a nitrogen atmosphere has resulted in the ferrite-austenite transformation. For the highest milling times (96 h), there was evidence of the amorphization process, which was detected by the typical broadening of the XRD peaks [19].

Another relevant aspect of the alloyed powders is the size of the particles, which gets smaller as the milling time increases, though the size is never regular, Fig. 2. In fact, for 72 and $96 \mathrm{~h}$ of milling, there were many particles with sizes on the micrometer scale, Fig. $2 \mathrm{c}$ and $\mathrm{d}$. This seriously affected compressibility. The only way to obtain PM samples for those powders was to apply a presintering before compaction and conventional sintering. This additional process was to heat the loose powders at $950{ }^{\circ} \mathrm{C}$ for 60 min in a $\mathrm{N}_{2}-\mathrm{H}_{2}(95 \%-5 \%)$ atmosphere and slow furnace cooling. In this way, some aggregates were obtained, and compaction and sintering was then possible. This was also the reason why no longer milling times were chosen. In addition, the amount of the amorphous phase would have increased [19]. It is also important to remark that the powders with $48 \mathrm{~h}$ of milling mostly showed a ferritic microstructure; moreover, for PM samples, it is possible to reach a full austenitic microstructure under certain sintering conditions, as it will be described in section 3.3.

\subsection{Porosity and density}

The porosity and density of the PM samples obtained by fast cooling are shown in Table 2. Furnace-cooling affects porosity very little. It can be seen that, by increasing the milling time to $48 \mathrm{~h}$, the density increases and the porosity decreases. For longer milling times, the porosity and density do not follow the same trend due to the pre-sintering step. The efficacy of compaction and sintering is heavily dependent on the size of the powder particles. Salahinejad et al. [20] explained this by considering that the amorphous phase, and therefore the hardness and the resistance to plastic deformation, increased with the milling time, which made compaction more difficult. After this analysis, it seems that, from a practical point of view, $48 \mathrm{~h}$ of milling is adequate for the purpose of this
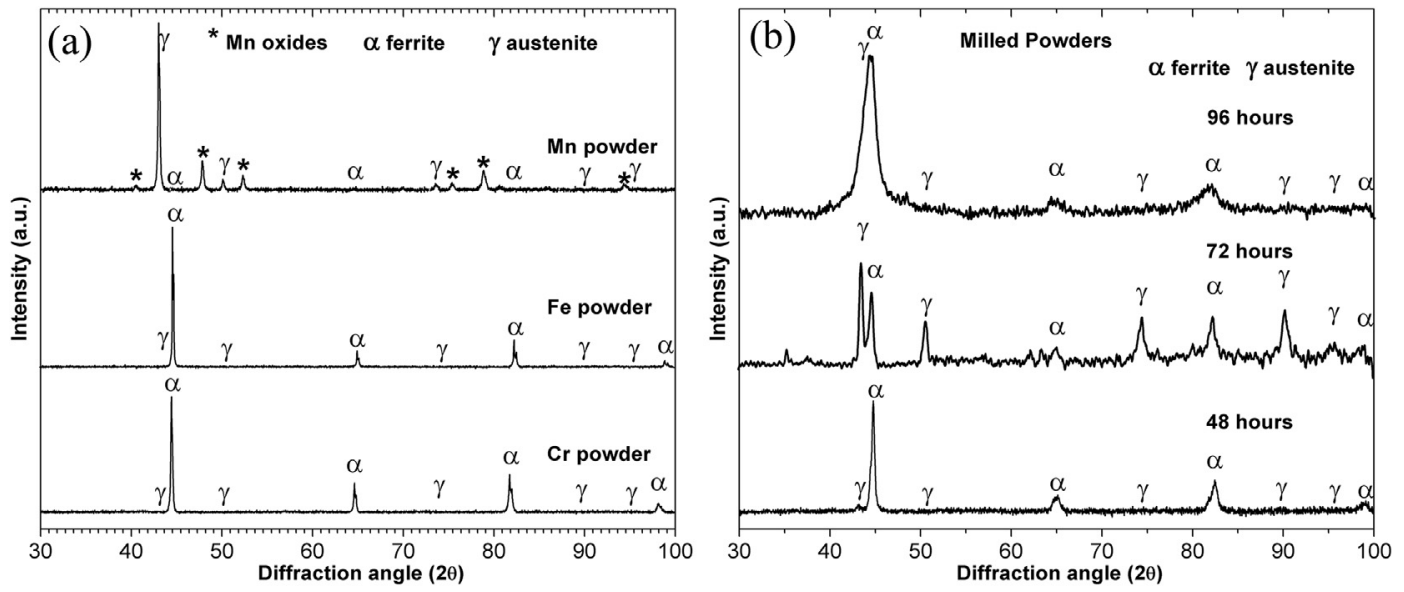

Fig. 1. XRD diffractograms of (a) Mn, Fe and Cr elemental powders and (b) alloyed powders with 48, 72 and $96 \mathrm{~h}$ of milling. 

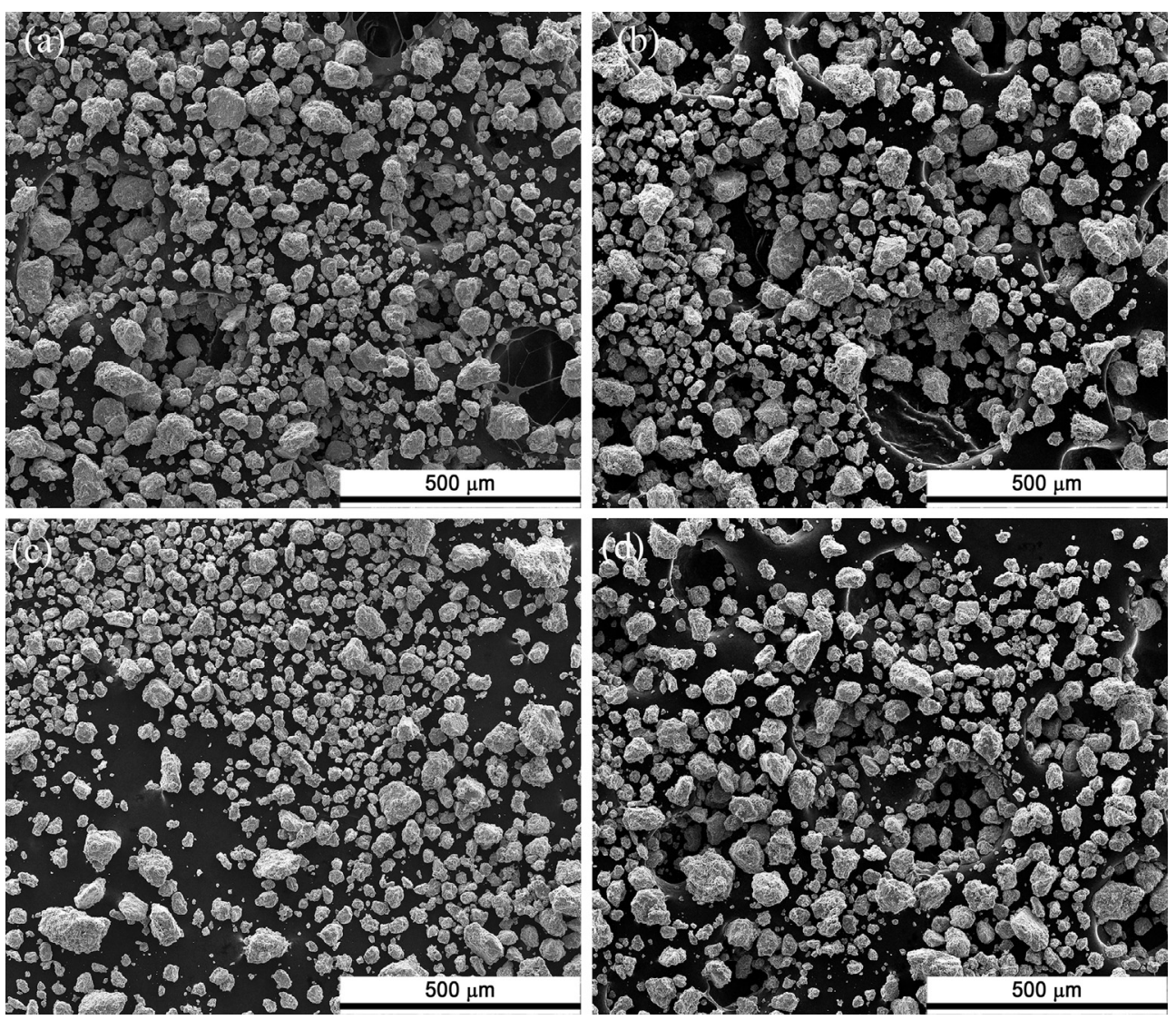

Fig. 2. SEM of mechanically alloyed powders after (a) 36, (b) 48, (c) 72 and (d) 96 h of milling.

work. Some further considerations also support this statement.

Fig. 3 shows the polished surfaces of some PM samples. There was no evidence of primary powder particles after $48 \mathrm{~h}$ of milling time (Fig. $3 \mathrm{~b}$ and c), which indicated that the sintering process was correct. Increasing the milling time promoted a higher number of pores of smaller size. Table 3 shows the porosity and density values of PM samples after a milling time of $48 \mathrm{~h}$. The sintering atmosphere is the greatest influencing factor in the porosity. The retarding densification process of nitrogen is well known, and occupies interstitial sites and promotes an increase in atomic packing. This originates a decrease in the atomic diffusion coefficients and, therefore, higher porosity.

\subsection{Optical metallography and SEM/EDS}

Microstructural characterization is quite a complex task, since optical metallography does not have enough resolution for a complete study. Only a secondary phase of brilliant aspect inserted in the matrix can be clearly observed. The amount diminished with the milling time, see Fig. 4. This phase was of great hardness ( $>1000$ HV) and was identified by SEM/EDS as rich in $\mathrm{Cr}$ and $\mathrm{N}$, row 1 of

Table 2

Average porosity and density of PM samples after water-cooling process.

\begin{tabular}{lll}
\hline Sample & Porosity $(\%)$ & Density $\left(\mathrm{g} / \mathrm{cm}^{3}\right)$ \\
\hline $24-N-W C$ & 12.87 & 6.07 \\
$36-N-W C$ & 12.06 & 6.11 \\
$48-N-W C$ & 11.5 & 6.49 \\
$72-N-W C$ & 12.65 & 6.09 \\
$96-N-W C$ & 12.18 & 6.21 \\
\hline
\end{tabular}

Table 4 and Fig. 5 a.

For the samples sintered in nitrogen and water-cooled, the transformation from ferrite to austenite was favoured with the increase in the milling time. This means that alloying was taking place as the milling time increased. The microstructure of 48-N-WC is shown in Fig. 5b. This matrix was completely formed by austenite of very fine grains and with the typical composition of the $\gamma$ phase, row 2 of Table 4 . Some dispersed precipitates in boundary grains were identified as complex oxides of $\mathrm{Fe}-\mathrm{Cr}-\mathrm{Mn}$, row 3 of Table 4.

Slow cooling of the samples sintered in nitrogen was not enough to reveal an austenitic microstructure. Their matrix was not homogeneous, as two phases of different tonality were identified, Fig. $5 \mathrm{c}$ and rows 4 and 5 of Table 4. The dark zones could be identified as austenite richer in $\mathrm{Cr}$ and $\mathrm{Mn}$, the light zone could be ferrite. The $\mathrm{Cr}$ content is lower than for water-cooled samples, which agrees with the higher amount of precipitates dispersed in the matrix, Fig. $5 \mathrm{~d}$ and row 6 of Table 4 . However, when this $48-\mathrm{N}-$ FC sample was annealed at $1050{ }^{\circ} \mathrm{C}$ for $60 \mathrm{~min}$ in argon atmosphere, resulting into the $48-\mathrm{N}-\mathrm{FC}-\mathrm{A}$ sample, the microstructure was austenitic, Fig. 5f, and similar to 48-N-WC. In this sense, with these two samples, the main objective was reached as austenite was obtained. Nevertheless, $48-\mathrm{N}-\mathrm{WC}$ is a much shorter route and a more homogeneous microstructure is obtained.

The sample sintered in a vacuum presented a more homogeneous microstructure. However, the SEM study revealed two different regions, marked in Fig. 5e as zones 1 and 2. The EDS analysis indicated that zone 1 is richer in $\mathrm{Fe}$ and $\mathrm{Cr}$ and poorer in Mn than zone 2, rows 7 and 8 of Table 4 . Zone 1 could be identified as ferrite, while zone 2, according to the Schaeffler diagram, could be identified as the mixed constituent of ferrite-austenitemartensite, already identified in some other PM SS sintered in a 


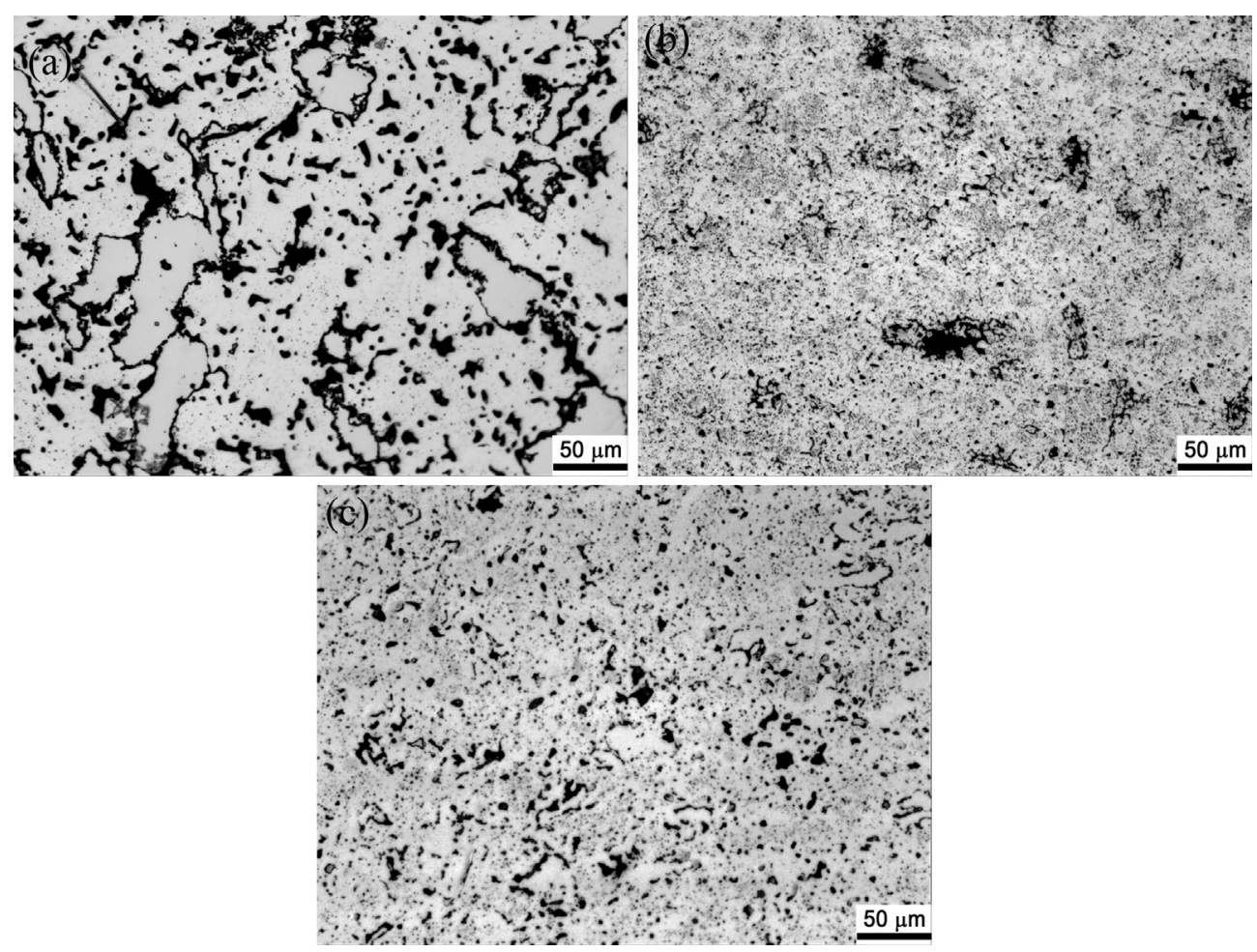

Fig. 3. Optical micrographs of polished PM samples: (a) 24-N-WC, (b) 48-N-WC and (c) 48-V-FC.

Table 3

Average porosity and density of PM samples after $48 \mathrm{~h}$ of milling.

\begin{tabular}{lll}
\hline Sample & Porosity $(\%)$ & Density $\left(\mathrm{g} / \mathrm{cm}^{3}\right)$ \\
\hline $48-N-W C$ & 11.50 & 6.49 \\
$48-N-F C$ & 11.79 & 6.08 \\
$48-N-F C-A$ & 10.58 & 6.44 \\
$48-V-F C$ & 6.25 & 6.84 \\
\hline
\end{tabular}

vacuum [37].

It is relevant to observe a content of nitrogen quite different for powders with $48 \mathrm{~h}$ of milling sintered in a vacuum or sintered in nitrogen. When the sample was sintered in a vacuum, the nitrogen content did not increase as compared to its content in the powders. But when sintered in $\mathrm{N}_{2}-\mathrm{H}_{2}(95 \%-5 \%)$, the final nitrogen content was $0.98 \pm 0.06$ wt.\%, which agrees with the previous discussion.

\subsection{Phase identification by magnetism and XRD analysis}

Since ferrite is magnetic but austenite is not, magnetic measurement is a good technique to determine the degree of transformation from ferrite to austenite. XRD analysis also helps in this sense.

Table 5 shows the volume fraction of magnetic content measured by a ferritscope (in ferrite \%) for every sample. For the samples sintered in nitrogen and water-cooled, it was clear that as the milling time increases, the ferrite was being transformed into austenite. The austenitic microstructure was almost fully austenite after a milling time of $48 \mathrm{~h}$. It can also be seen how the furnacecooled samples were not adequate, since a full transformation in austenite was not obtained. In addition, annealing (N-FC-A) gives a good result for the sample with $48 \mathrm{~h}$ of milling. The other furnacecooled samples showed a magnetic response, so they were far from being fully austenite. The amorphization process also influences the magnetic behaviour, since the formation of this phase delays the ferrite-austenite transformation [29]. This phenomenon is of consideration for milling times as long as 72 and $96 \mathrm{~h}$.

The transformation of ferrite into austenite was also confirmed by the XRD study of PM samples. Fig. 6a shows that, for the $36 \mathrm{~h}$ of milling, the peaks of ferrite are still detected. However, after $48 \mathrm{~h}$, the ferrite peaks had almost disappeared and only the austenite peaks were visible. A small shift to lower angles, typical of the presence of nitrogen in solid solution, is also observed.

The XRD pattern of 48-N-FC shows the peaks of the ferrite and the austenite plus some peaks assigned to complex nitrides of $\mathrm{Cr}$ and $\mathrm{Fe}$ of the type $(\mathrm{Cr}, \mathrm{Fe})_{2} \mathrm{~N}_{1-\mathrm{x}}$. The amount of precipitates is relatively small in comparison to the bulk of the samples. Consequently, XRD does not have enough resolution to give information about precipitates. An approach to solving this problem is to perform a so-called bulk extraction prior to the XRD analysis. The metal matrix is electrolytically dissolved and the residues (formed by the undissolved precipitates) are XRD analysed. Fig. 6b shows the results from this preparation for $48-\mathrm{N}-\mathrm{FC}$ and $48-\mathrm{N}-\mathrm{WC}$. Chromium nitrides type $\mathrm{M}_{2} \mathrm{X}(\mathrm{M}=\mathrm{Cr}$, Mo and $\mathrm{X}=\mathrm{N}, \mathrm{C})$ and chromium-iron nitrides type $(\mathrm{CrFe})_{\mathrm{x}} \mathrm{X}_{1-\mathrm{x}}$ were identified for both samples. The amount of these phases is clearly higher for $48-\mathrm{N}-\mathrm{FC}$ than for $48-\mathrm{N}-\mathrm{WC}$. Additionally, the former showed some nitride precipitates absent for the latter. These precipitates were identified as chromium nitride type $\mathrm{CrN}$ and iron nitride type $\mathrm{Fe}_{3} \mathrm{~N}$. Finally, both contained amounts of manganese oxides, such as $\mathrm{Mn}_{3} \mathrm{O}_{4}$ and $\mathrm{Cr}_{2} \mathrm{MnO}_{4}$. Therefore, fast cooling for samples sintered in nitrogen is recommended because the amount of nitride precipitates is lower.

\subsection{Mechanical behaviour measured by hardness test}

The results of the Vickers hardness and microhardness tests confirm that the milling time of the powders is a relevant factor for the hardness of the PM samples (Fig. 7). These Vickers hardness 


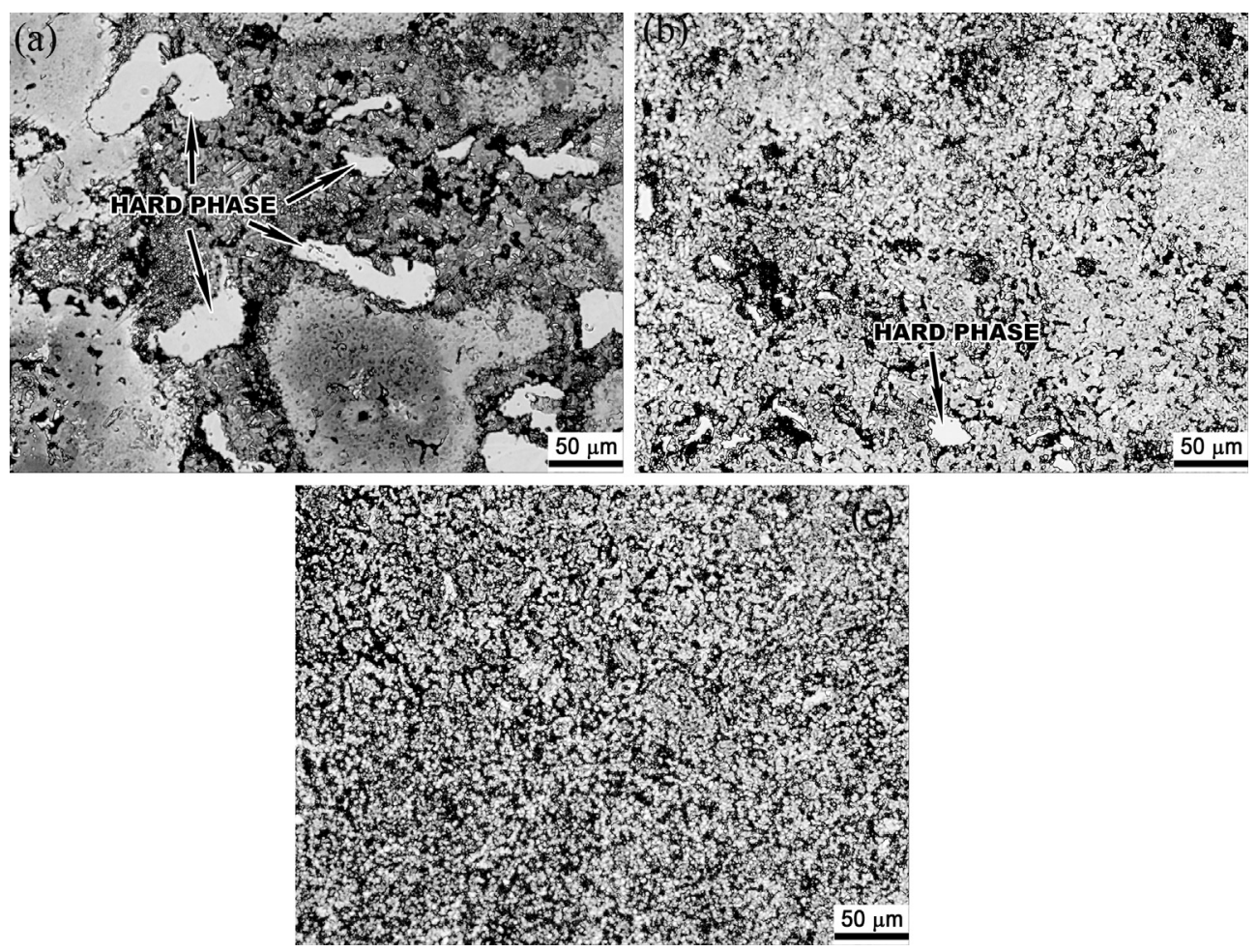

Fig. 4. Optical micrographs of water-cooled samples sintered in nitrogen for milling times of (a) 24 , (b) 48 and (c) 96 h. Fry reagent used as etchant.

Table 4

EDS analysis of PM samples after $48 \mathrm{~h}$ of milling. See Fig. 5 for identification zones.

\begin{tabular}{|c|c|c|c|c|c|c|}
\hline Row number & Sample & $\mathrm{Fe}(w \mathrm{t} . \%)$ & $\mathrm{Cr}(\mathrm{wt} . \%)$ & Mn (wt.\%) & N (wt.\%) & 0 (wt.\%) \\
\hline 1 & 48-N-WC Nitride islands & 05.36 & 62.17 & 02.18 & 24.79 & 05.49 \\
\hline 2 & 48-N-WC Austenite & 69.36 & 18.06 & 07.51 & 05.08 & - \\
\hline 3 & 48-N-WC Oxides & 38.13 & 20.21 & 09.41 & - & 26.69 \\
\hline 4 & 48-N-FC Austenite & 69.84 & 16.68 & 07.75 & 05.73 & - \\
\hline 5 & 48-N-FC Ferrite & 78.77 & 10.77 & 06.03 & 04.44 & - \\
\hline 6 & 48-N-FC Precipitates & 47.82 & 19.97 & 06.46 & 20.22 & 05.53 \\
\hline 7 & 48-V-FC Zone 1 & 74.38 & 19.95 & 05.67 & - & - \\
\hline 8 & 48-N-FC Zone 2 & 75.30 & 16.27 & 08.43 & - & - \\
\hline
\end{tabular}

values are low in comparison with those expected from a wrought austenitic SS, which stresses the idea that porosity reduces the hardness. On the other hand, the microhardness values at pore-free zones were found to be considerable, especially for lower milling times. This hardening could be explained by taking into account the strengthening effect of nitrogen and the Hall-Petch equation [38].

The nitrogen in austenitic SS is an effective element, not only in solid solution strengthening, but also in grain size strengthening [3]; so an increase in the mechanical properties should be expected by increasing the milling time, as there is more nitrogen in the solid solution. However, the opposite tendency was observed in this study. To explain this, the microstructural analysis must be accounted for. A hard secondary phase, identified as chromium nitrides, was present for PM samples with low milling times. This could well be what is responsible for the high hardness registered in these samples. As the milling time increased, these precipitates were broken down and more nitrogen was dissolved in the matrix. Therefore, a decrease in hardness was expected.

A second point to analyse is the effect of the sintering conditions, Fig. 7. It can be seen that, for each milling time, the N-FC sample showed a higher value than its corresponding N-WC. This relates with the fact commented in section 3.3, i.e., that for N-FC samples, there was a higher amount of precipitates dispersed in the matrix than for N-WC. Finally, Fig. 7 also shows more detailed information of samples with $48 \mathrm{~h}$ of milling. It can be seen that, for the sample sintered in a vacuum, 48-V-FC had a higher hardness than the samples sintered in nitrogen. The mixed constituent [37], rich in martensite, could explain this. In addition, samples sintered in a vacuum were denser than those sintered in nitrogen. For samples sintered in nitrogen, there was a clear improvement in microhardness for the furnace cooled sample due to the higher content of precipitates. The sample submitted to annealing originated the dissolution of some precipitates, so the hardness decreased. The hardness of 48-N- FC-A was similar to that of 48-N$\mathrm{WC}$, and both were formed by austenite with dissolved nitrogen.

\subsection{Corrosion behaviour in biological media}

It should not be forgotten that one of the main issues of this work was to find Ni-free austenitic SS for use in biological applications. Therefore, what is studied here is the corrosion behaviour via anodic polarization measurements in a biological media such as the typical PBS. One more point is that these PM samples are porous materials and there is really no way to evaluate the wetted surface 

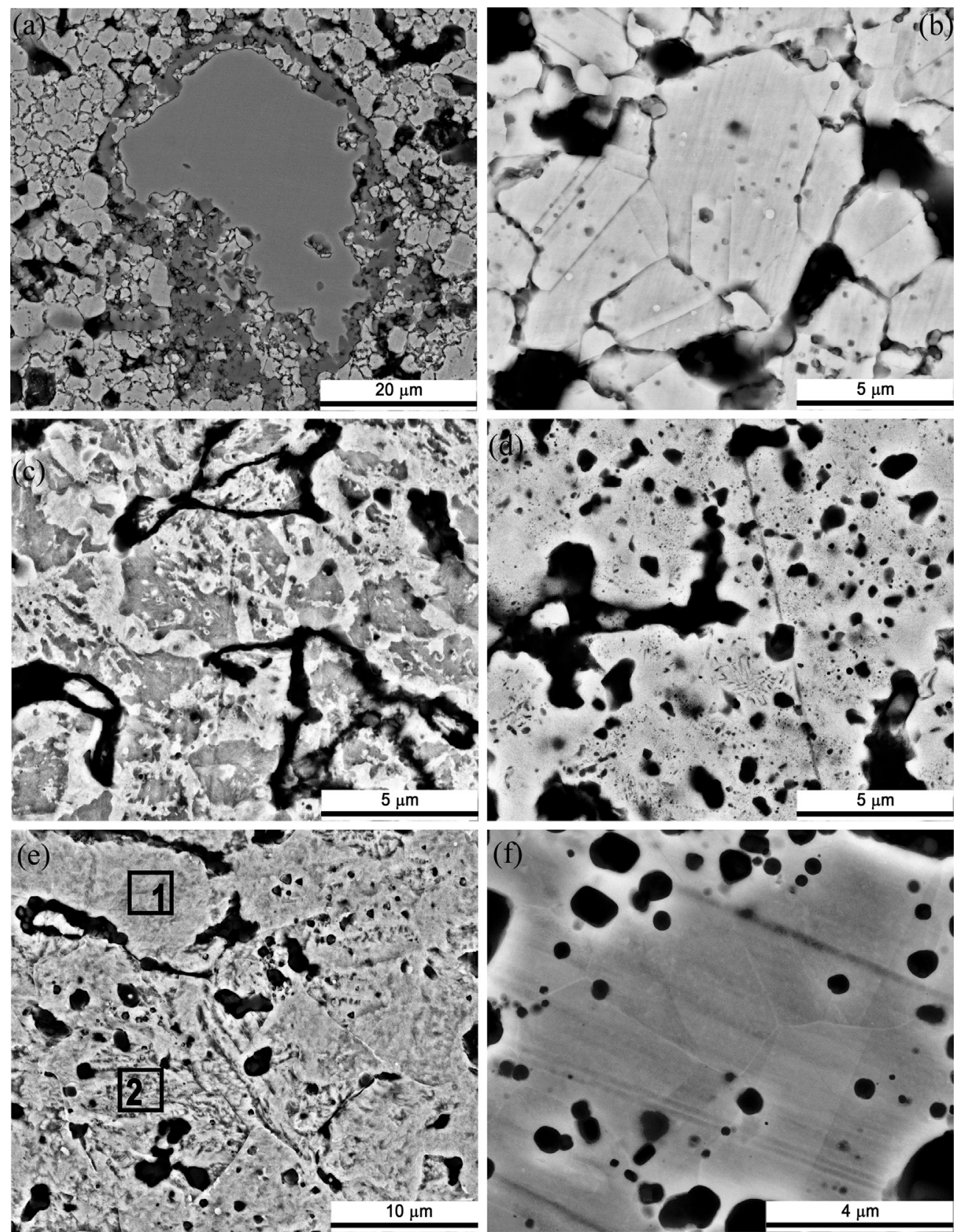

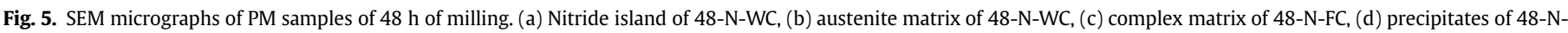
FC, (e) matrix of 48-V-FC and (f) austenite matrix of 48-N-FC-A.

Table 5

Volume fraction of magnetic content of PM samples measured by a ferritscope (in ferrite \%) (measuring accuracy: \pm 0.05 for $0-1 \%$ range, $\pm 0.15 \%$ for $0-3 \%$ range, $\pm 0.6 \%$ for $0-12 \%$ range and $\pm 2.5 \%$ for $0-50 \%$ range).

\begin{tabular}{|c|c|c|c|c|c|}
\hline \multirow[t]{2}{*}{ Sample } & \multicolumn{5}{|c|}{ Milling time } \\
\hline & $24 \mathrm{~h}$ & $36 \mathrm{~h}$ & $48 \mathrm{~h}$ & $72 \mathrm{~h}$ & $96 \mathrm{~h}$ \\
\hline N-WC & 14.00 & 2.30 & 0.33 & 0.55 & 0.30 \\
\hline N-FC & 18.40 & 19.30 & 10.40 & 18.60 & 24.60 \\
\hline N-FC-A & 4.80 & 1.60 & 0.62 & 5.50 & 11.20 \\
\hline V-FC & 85.20 & 80.50 & 67.20 & 66.20 & 55.20 \\
\hline
\end{tabular}

in every sample. Therefore, the current density can only be a rough estimation of the real values. Here, the surface value used was the flat area of the sample, consequently porosity was ignored.

First, the influence of the milling time will be analysed. Fig. 8a shows the anodic polarization curves of samples sintered in nitrogen and water-cooled for 24, 36, 48, 72 and $96 \mathrm{~h}$ of milling the powders. The anodic behaviour is clearly different as a function of the milling time. Samples with $48 \mathrm{~h}$ of milling or less showed continuous dissolution, while samples with 72 and 96 h showed a passivity range and a real pitting potential was found. The noblest corrosion potential corresponded to $96-\mathrm{N}-\mathrm{WC}$. For samples milled for 24,36 and $48 \mathrm{~h}$, the anodic curve morphology was similar, but with slightly lower current densities and nobler potential corrosion as the milling time increased.

Since it is known that, for samples with low milling times, the presence of the chromium nitride areas was relevant, this did not 

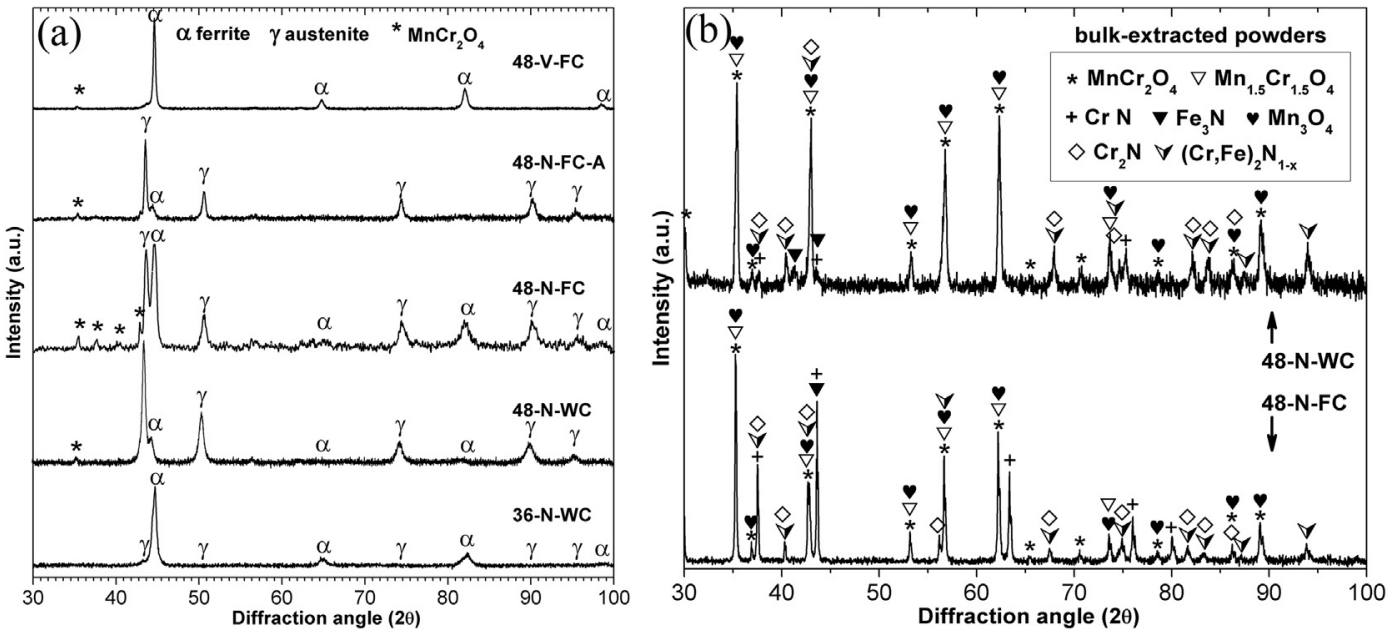

Fig. 6. Diffractograms of (a) 36-N-WC, 48-N-WC, 48-N-FC, 48-N-FC-A and 48-V-FC. (b) bulk extracted powders of 48-N-WC and 48-N-FC.

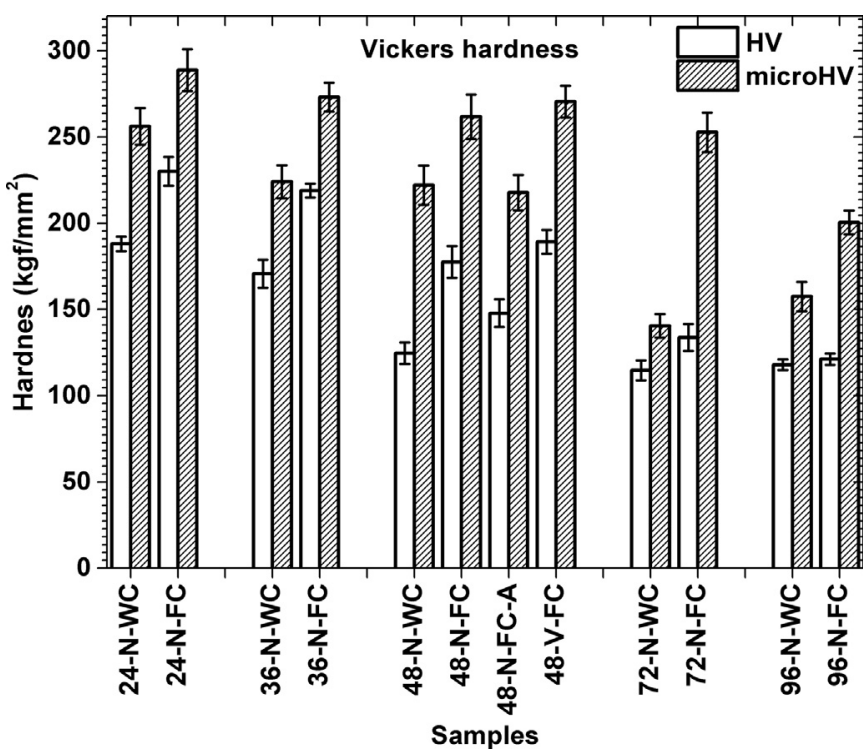

Fig. 7. (a) Vickers hardness and (b) microhardness of the samples.

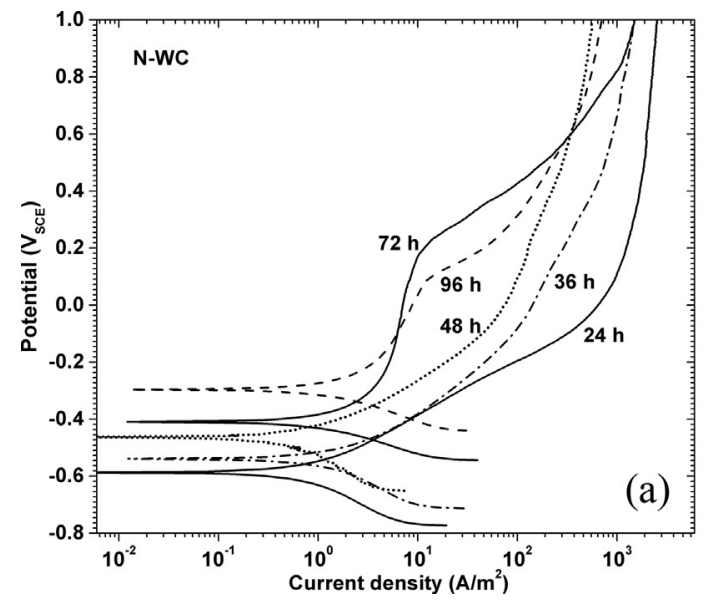

Fig. 8. Influence of the milling time on the anodic polarization curves of samples sintered in nitrogen and (a) water-cooled, and (b) furnace-cooled.

allow the passive films to be stable, so a higher current density was registered. The microstructures of $72-\mathrm{N}-\mathrm{WC}$ and $96-\mathrm{N}-\mathrm{WC}$ were much more homogeneous, so a better corrosion behaviour was expected, Fig. 8a.

For samples sintered in nitrogen and furnace-cooled, the effect was similar, Fig. 8b, though differences were less relevant. Milling times of 72 and 96 h do not show a clear improvement because it has been verified that the microstructure was far from being pure austenite.

The effect of sintering conditions on anodic behaviour for samples obtained with $48 \mathrm{~h}$ of milling is shown in Fig. 9a. Fast cooling by water quenching exhibited a very positive effect on the anodic behaviour. This could be related with an austenitic microstructure with nitrogen in solid solution and free of nitrogen precipitates. Consequently, 48-N-WC showed a more noble potential and lower current density than $48-\mathrm{N}-\mathrm{FC}$. Annealing had a positive effect on the microstructure of 48-N-FC in the sense that it favoured the presence of austenite and the dissolution of the precipitates. Accordingly, the anodic behaviour was very similar for $48-\mathrm{N}-\mathrm{WC}$ and 48-N-FC-A. This also confirms the beneficial effect of nitrogen on corrosion behaviour when dissolved in the austenite.

The samples sintered in a vacuum showed nobler corrosion potential than samples sintered in nitrogen. These samples were denser and this was an important factor in corrosion resistance.

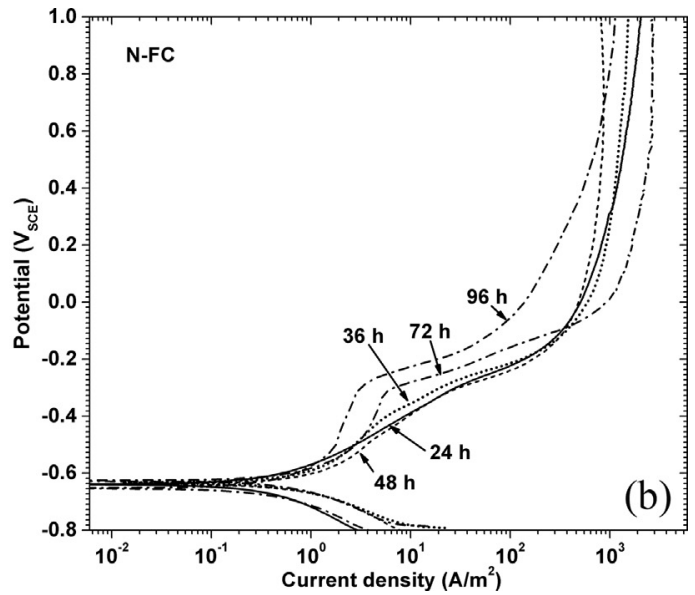



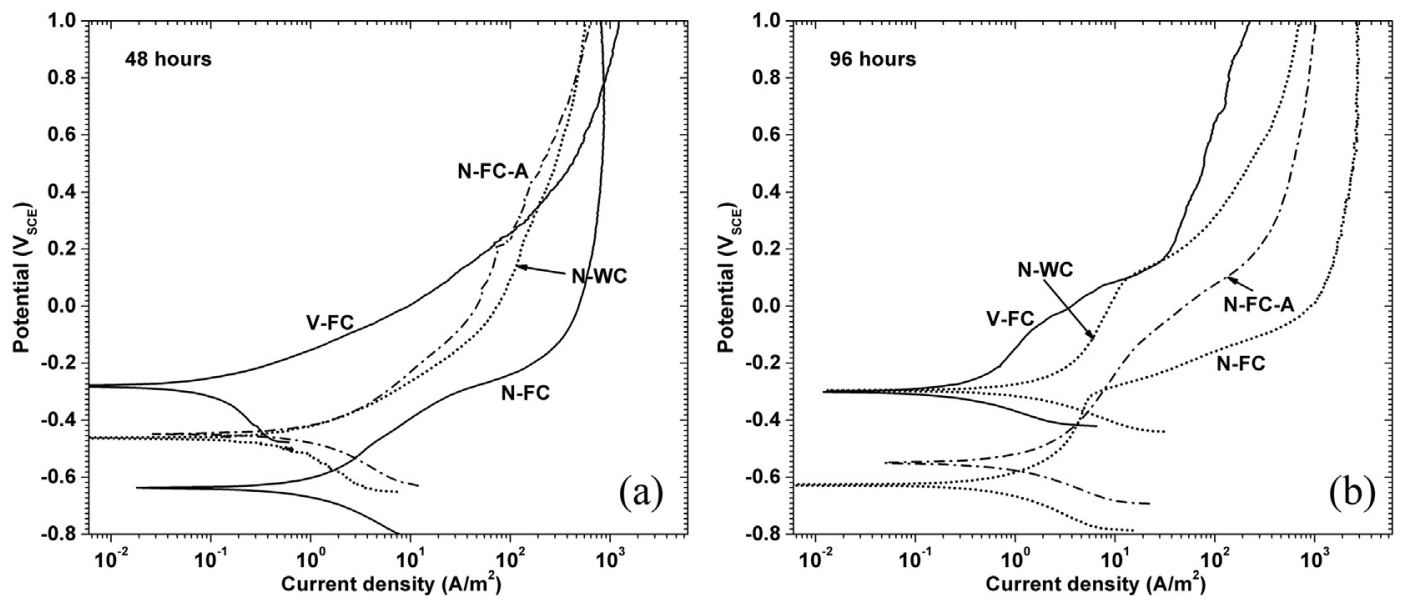

Fig. 9. Influence of the sintering condition on the anodic polarization curves of samples with (a) $48 \mathrm{~h}$ and (b) $96 \mathrm{~h}$ of milling.

Nevertheless, they were magnetic, so they are not suitable for biological applications. For samples with higher milling times, Fig. 9b, the behaviour was similar to that shown with $48 \mathrm{~h}$.

Table 6 shows the corrosion potentials and corrosion current densities calculated by Tafel analysis. Samples sintered in nitrogen and water cooled, from powders with $48 \mathrm{~h}$ of milling, showed the lowest corrosion current density; while the corrosion potential was nobler for samples with longer milling times. For 48-N samples, the water-cooling process was the most adequate, though annealing reduced the corrosion rate to a third of that of furnace-cooled samples, so it was also recommended. The Tafel values confirmed that samples sintered in a vacuum showed the best behaviour, although their magnetism advises against their use as biomaterial.

\section{Conclusions}

Mechanical alloying is the technique that can allow powders to be made without nickel, but potentially with the ability to obtain austenitic stainless steels. It is necessary to compact and sinter the samples, so porous materials are obtained.

The milling time of elemental powders of $\mathrm{Fe}, \mathrm{Cr}$, $\mathrm{Mn}$ and $\mathrm{C}$ in nitrogen atmosphere is determinant for obtaining an alloyed steel. Under the operational parameters of this work, not more than $48 \mathrm{~h}$ of milling is recommended if a crystalline microstructure is wanted.

The sintering atmosphere and the subsequent cooling process from sintering temperature are the main factors, together with the milling times, that determine what type of sample is obtained. A complete microstructural study is carried out. Techniques such as optical metallography, SEM/EDS and XRD are used. Ferrite,

Table 6

Corrosion potential and corrosion current density calculated by Tafel.

\begin{tabular}{lll}
\hline Sample & $\begin{array}{l}\text { Corrosion current } \\
\text { density }\left(\mathrm{A} / \mathrm{m}^{2}\right)\end{array}$ & $\begin{array}{l}\text { Corrosion potential } \\
\left(\mathrm{V}_{\mathrm{SCE}}\right)\end{array}$ \\
\hline $24-\mathrm{N}-\mathrm{WC}$ & 1.17 & -0.587 \\
$36-\mathrm{N}-W C$ & 1.65 & -0.539 \\
$48-\mathrm{N}-W C$ & 0.21 & -0.442 \\
$72-\mathrm{N}-W C$ & 0.82 & -0.409 \\
$96-\mathrm{N}-W C$ & 0.74 & -0.296 \\
$48-\mathrm{N}-\mathrm{FC}$ & 1.09 & -0.653 \\
$48-\mathrm{N}-\mathrm{FC}-\mathrm{A}$ & 0.31 & -0.448 \\
$48-\mathrm{V}-\mathrm{FC}$ & 0.14 & -0.281 \\
$96-\mathrm{N}-\mathrm{FC}$ & 1.21 & -0.627 \\
$96-\mathrm{N}-\mathrm{FC}-\mathrm{A}$ & 0.67 & -0.547 \\
$96-\mathrm{V}-\mathrm{FC}$ & 0.48 & -0.299 \\
\hline
\end{tabular}

austenite, oxides and some other precipitates are identified. The powder metallurgy sample made from powder milled for $48 \mathrm{~h}$, sintered in nitrogen and water-cooled, is the one that shows a clear austenite. The magnetism study confirms this statement.

Mechanical characterization by Vickers hardness and microhardness is also carried out. The presence of nitride precipitates is the main factor. Therefore, the PM samples with the lower milling times show the highest hardness for any sinter cooling process.

Biocorrosion is studied by means of anodic polarization curves in a simulated body fluid such as PBS. Sintering in nitrogen and water-cooling is the advised process to obtain an acceptable corrosion behaviour. Higher milling times than $48 \mathrm{~h}$ provide a better anodic behaviour than the sample with $48 \mathrm{~h}$ of milling. However, the need for a pre-sintering step would advise against its use, since a new long step is required.

\section{References}

[1] K. Alvarez, K. Sato, S.K. Hyun, H. Nakajim, Fabrication and properties of lotus type porous nickel-free stainless steel for biomedical applications, Mater. Sci. Eng. C 28 (2008) 44-50.

[2] M. Fini, A.N. Nicoli, P. Torricelli, G. Giavaresi, V. Borsari, H. Lenger, J. Bernauer, R. Giardino, R. Chiesa, A. Cigada, A new austenitic stainless steel with negligible nickel content: an in vitro and in vivo comparative investigation, Biomaterials 24 (2003) 4929-4939.

[3] H. Hännimen, J. Romu, R. Ilola, J. Tervo, A. Laitinen, Effects of processing and manufacturing of high nitrogen-containing steels on their mechanical, corrosion and wear properties, J. Mater. Process. Technol. 117 (2001) $424-430$.

[4] P.C. Pistorius, M. du Toit, Low-nickel austenitic stainless steels: metallurgical constraints, in: The 12th International Ferroalloys Congress, Helsinki, Finland, June 6-9, 2010, pp. 911-918.

[5] M. Talha, C.K. Behera, O.P. Sinha, A review on nickel-free nitrogen containing austenitic stainless steels for biomedical applications, Mater. Sci. Eng. C 33 (2013) 3563-3575.

[6] C. Garcia, F. Martin, P. de Tiedra, L. García Cambronero, Pitting corrosion behaviour of PM austenitic stainless steels sintered in nitrogen-hydrogen atmosphere, Corros. Sci. 49 (2007) 1718-1736.

[7] M. Sumita, T. Hanava, S.H. Teoh, Development of nitrogen containing nickelfree austenitic stainless steels for metallic biomaterials-review, Mater. Sci. Eng. C 24 (2004) 753-760.

[8] J.W. Simmons, Overview: high-nitrogen alloying of stainless steels, Mater. Sci. Eng. A 207 (1996) 159-169.

[9] J.W. Simmons, W.E. Kemp, J.S. Dunning, The P/M processing of high- nitrogen stainless steels, JOM 48 (1996) 20-23.

[10] C. Suryanarayana, Mechanical alloying and milling, Prog. Mater. Sci. 46 (2001) $1-184$.

[11] F. Tehrani, M.A. Golozar, M.H. Abbasi, M. Panjepour, Characterization of nanostructured high nitrogen $\mathrm{Fe}-18 \mathrm{Cr}-\mathrm{xMn}-4 \mathrm{Mo}$ austenitic stainless Steel prepared by mechanical alloying, Mater. Sci. Eng. A 534 (2012) 203-208.

[12] R. Amini, E. Salahinejad, E. Askari Bajestani, M.J. Hadianfrad, On the general outline of physical properties of amorphous-nanocrystalline $\mathrm{Fe}-\mathrm{Cr}-\mathrm{Mn}-\mathrm{N}$ alloy powders prepared by mechanical alloying under nitrogen, J. Alloys Compd. 
509 (2011) 3252-3256.

[13] H. Miura, H. Ogawa, Preparation of nanocrystalline high-nitrogen stainless steel powders by mechanical alloying and their hot compaction, Mater. Trans. 42 (2001) 2368-2373.

[14] M.H. Enayati, M.R. Bafandeh, Phase transitions in nanostructured $\mathrm{Fe}-\mathrm{Cr}-\mathrm{Ni}$ alloys prepared by mechanical alloying, J. Alloys Compd. 24 (2008) 228-232.

[15] F. Popa, O. Isnard, I. Chicinas, V. Pop, NiFeCuMo magnetic powders obtained by controlled mechanical alloying and annealing, J. Magn. Magn. Mater. 316 (2007) e900-e903.

[16] R. Amini, M.J. Hadianfard, E. Salahinejad, M. Marasi, T. Sritharan, Microstructural phase evaluation of high-nitrogen Fe-Cr-Mn alloy powders synthesized by the mechanical alloying process, J. Mater. Sci. 44 (2009) 136-148.

[17] E. Salahinejad, R. Amini, M.J. Hadianfard, Structural evolution during mechanical alloying of stainless steels under nitrogen, Powder Technol. 215-216 (2012) 247-253.

[18] R. Amini, E. Salahinejad, M.J. Hadianfard, M. Marasi, T. Sritharan, Characterization of $\mathrm{Fe}-\mathrm{Cr}-\mathrm{Mn}-\mathrm{N}$ amorphous powders with a supercooled liquid region developed by mechanical alloying, Mater. Sci. Eng. A 527 (2010) 1135-1142.

[19] R. Amini, H. Shokrollahi, El Salahinejad, M.J. Hadianfard, M. Marasi, T. Sritharan, Microstructural, thermal and magnetic properties of amorphous nanocrystalline FeCrMnN alloys prepared by mechanical alloying and subsequent heat treatment, J. Alloys Compd. 480 (2009) 617-624.

[20] E. Salahinejad, R. Amini, M. Marasi, T. Sritharan, M.J. Hadianfard, The effect of nitrogen on the glass-forming ability and micro-hardness of Fe-Cr-Mn-N amorphous alloys prepared by mechanical alloying, Mater. Chem. Phys. 118 (2009) $71-75$.

[21] E. Salahinejad, R. Amini, M.J. Hadianfard, Effect of milling time on structure and mechanical properties of porous nickel-free austenitic stainless stee processed by mechanical alloying and sintering, Mater. Sci. Eng. A 527 (2010) 5522-5527.

[22] E. Salahinejad, R. Amini, M. Marasi, M.J. Hadianfard, Microstructure and wear behavior of a porous nanocrystalline nickel-free austenitic stainless steel developed by powder metallurgy, Mater. Des. 31 (2010) 2259-2263.

[23] S. Fátima, V. Guido, L.Y. Cho, C. Pacheco, K. Regina, Porous stainless steel for biomedical applications, Mater. Res. 14 (2011) 208-215.

[24] L.J. Gibson, Biomechanics of cellular solids, J. Biomech. 38 (2005) 377-399.

[25] V.K. Balla, S. Bodhak, S. Bose, A. Bandyopadhyay, Porous tantalum structures for bone implants: fabrication, mechanical and in vitro biological properties, Acta Biomater. 6 (2010) 3349-3359.
[26] C. Garcia, F. Martin, Y. Blancoa, G. Herranz, Influence of sinter-cooling rate on the corrosion behavior of high-nitrogen, low-nickel powder metallurgy austenitic stainless steel, Corrosion 70 (2014) 1000-1007.

[27] ASTM F2581-12, Standard Specification for Wrought Nitrogen Strengthened 11 manganese-17chromium-3molybdenum Low-nickel Stainless Steel Alloy Bar and Wire for Surgical Implants (UNS S29225), ASTM International, West Conshohocken, PA, 2012

[28] M. Javanbakht, E. Salahinejad, M.J. Hadianfard, The effect of sintering temperature on the structure and mechanical properties of medical-grade powder metallurgy stainless steels, Powder Technol. 289 (2016) 37-43.

[29] E. Salahinejad, M.J. Hadianfard, M. Ghaffari, R. Amini, Sh. Bagheri Mashhadi, A.K. Okyay, Microstructural characterization of medical-grade stainless steel powders prepared by mechanical alloying and subsequent annealing, Adv. Powder Technol. 24 (2013) 605-608.

[30] A. Kocijan, I. Milosev, B. Pihlar, The influence of complexing agent and proteins on the corrosion of stainless steels and their metal components, J. Mater. Sci. Mater. Med. 14 (2003) 69-77.

[31] A. Kocijan, D. Merl, M. Jenko, The corrosion behavior of austenitic and duplex stainless steels in artificial saliva, Corros. Sci. 53 (2011) 776-783.

[32] S. Karimi, T. Nickchi, A. Alfantazi, Effects of bovine serum albumin on the corrosion behavior of AISI 316L, Co-28Cr-6Mo, and Ti-6Al-4V alloys in phosphate buffered saline solutions, Corros. Sci. 53 (2011) 3262-3272.

[33] A. Shahryari, S. Omanovic, J.A. Szpunar, Electrochemical formation of highly pitting resistant passive films on a biomedical grade 316LVM stainless steel surface, Mater. Sci. Eng. C 28 (2008) 94-106.

[34] ASTM Standard A262-91, Standard Practice for Detecting Susceptibility to Intergranular Attack on Austenitic Stainless Steels, ASTM International, West Conshohocken, PA, 1993, pp. 1-18.

[35] E. Mosca (Ed.), Powder Metallurgy: Criteria for Design and Inspection, AMMA, Turin, Italy, 1984, pp. 70-72.

[36] ASTM Standard G-5-87, Standard Reference Test Method for Making Potentiostatic and Potentiodynamic Anodic Polarization Measurements, ASTM International, West Conshohocken, PA, 1993, pp. 71-75.

[37] C. Garcia, F. Martin, Y. Blanco, M.P. De Tiedra, M.L. Aparicio, Influence of sintering under nitrogen atmosphere on microstructures of powder metallurgy duplex stainless steels, Metall. Mater. Trans. A 40 (2009) 292-301.

[38] ASM Handbook, Volume 8, Mechanical Testing and Evaluation, ASM International, Materials Park, OH, 2000, p. 29. 